\title{
Splenic Preservation Just Might Be Reasonable for Patients with Left-Sided Pancreatic Cancer
}

\author{
Charles R. Scoggins, MD, MBA
}

The Hiram C. Polk, Jr., MD Department of Surgery, The University of Louisville, Louisville, KY

Pancreatic cancer continues to be one of the most lethal malignancies, and efforts to improve patient survival are often impacted by the narrow confines of the lesser sac and the biologic aggressiveness of the cancer. Multiple factors impact outcome, including tumor size, nodal status, and margin status. For patients with cancers in the neck, body, or tail of the pancreas, left-sided pancreatectomy is the surgical procedure of choice. This can be done using either open or minimally invasive techniques. ${ }^{1}$ Surgeons have long debated the role of splenectomy as part of left-sided pancreatectomy, especially in the setting of cancer.

In this issue of Annals of Surgical Oncology, Collard and colleagues question the role of routine splenectomy at the time of left-sided pancreatectomy for cancer. Specifically, they looked to the splenic hilum for both hilar nodal metastases as well as direct tumor extension into the splenic hilum and/or spleen. ${ }^{2}$ These two issues, viz. nodal involvement in station 10 and direct splenic involvement by tumor, are intertwined but best considered separately.

First, let us look at the nodal issue. It is well known that pancreatic adenocarcinoma prognosis is associated with nodal metastasis. Ensuring a good nodal harvest is imperative, yet extended lymphadenectomies have not been associated with improved outcomes. ${ }^{3}$ In the current article, Collard and colleagues report that a very high number of peripancreatic nodes were found, speaking to the diligence of the pathologists involved. Upon reassessment, including redissecting the splenic hilum, the median number of nodes in station 10 was 2 , with no station 10 nodes found in $40 \%$ of patients. Interestingly, no cases of nodal upstaging

\footnotetext{
(C) Society of Surgical Oncology 2019
}

First Received: 5 December 2018;

Published Online: 23 January 2019

C. R. Scoggins, MD, MBA

e-mail: Charles.scoggins@louisville.edu occurred based on station 10 status. In fact, no patient had positive nodes in station 10, despite the fact that half of all patients were node positive. This suggests that adenocarcinoma cells from the pancreas do not flow towards the splenic hilum. If none of these nodes are positive, and extended lymphadenectomy strategies are not helpful for pancreatic cancer, then why should routine harvesting of the splenic hilar nodes be of any benefit to the patient?

The second issue centers around the risk of local tumor extension into the spleen. Collard and colleagues looked closely at direct tumor extension into either the splenic hilum and/or the spleen itself. They had blinded radiologists review the preoperative imaging for tumors either involving spleen or close $(1 \mathrm{~cm})$ and found that this was reliably found by both radiologists on the preoperative scan. This makes sense, as visualizing the tumor being right at the splenic hilum or extending onto the spleen should be rather straightforward. Therefore, it is entirely logical that tumors in the distal tip of the pancreatic tail are at high risk for local tumor extension into the spleen and, therefore, routine en bloc splenectomy is warranted.

So, what is the risk of splenectomy? Postsplenectomy sepsis is a risk, albeit rare with vaccines being available and effective. Indeed, this risk is exceedingly low. Elevated platelet count is possible, with the theoretical risk of hypercoagulability, albeit also low. Alterations in immunologic function are noted after splenectomy, and our understanding of the importance of immunomodulation in the perioperative setting is only now starting to develop. Furthermore, the impact of splenectomy on immunologic function relating to oncologic outcome is poorly understood, and it is entirely possible that further evidence will elicit important immune functions that have bearing on cancer-specific outcomes.

If one is going to preserve the spleen during a left-sided pancreatectomy, there are two basic techniques: splenic vessel preservation and Warshaw technique. ${ }^{4}$ Both are 
possible with either laparoscopic or open approaches, but the Warshaw technique is probably more appropriate for cases of pancreatic adenocarcinoma to improve margin clearance and nodal harvest along the splenic vessels. The Warshaw technique involves resection of the splenic artery and vein (which should allow for a wider posterior margin than the splenic vessel preservation technique) with division of the vessels distally in the splenic hilum. This preserves the short gastric vessels as the source of blood flow to the spleen. The Warshaw technique has been shown to be technically feasible when done laparoscopically ${ }^{5}$ with a very low risk of significant pancreatic fistula and complication rate, and very low risk for clinically significant splenic infarction. This manuscript ${ }^{4}$ was for mostly benign tumors, so no meaningful oncologic conclusions can be reached. Interestingly, half of the patients had at least some degree of splenic infarction, but none had total infarction. Most of those had recovered splenic perfusion by 3 months' time.

Ultimately, the authors are correct in their statement that a randomized trial would be necessary to answer this question definitively. Their data are thought-provoking and certainly hypothesis-generating. Perhaps we do not need to routinely remove the spleen when doing a left-sided pancreatectomy for adenocarcinoma. Only a properly done randomized trial can definitively answer that question. In the era of organ preservation, this is a reasonable and logical step.

\section{REFERENCES}

1. Kooby DA, Hawkins WG, Schmidt CM, Weber SM, Bentram DJ, Gillespie TW, Sellers JB, Merchant NB, Scoggins CR, Martin RCG, Kim HJ, Ahmad S, Cho CS, Parikh AA, Chu CK, Hamilton NA, Doyle CJ, Pinchot S, Hayman A, McClaine R, Nakeeb A, Staley CA, McMasters KM, Lillemoe KD. A multicenter analysis of distal pancreatectomy for adenocarcinoma: Is laparoscopic resection appropriate? J Am Coll Surg. 2010;210:779-87.

2. Collard M, Marchese T, Guedj N, Cauchy F, Chassaing C, Ronot M, Dokmak S, Soubrane O, Sauvanet A. Is routine splenectomy justified for all left-sided pancreatic cancers? Histological reappraisal of splenic hilar lymphadenectomy. Ann Surg Oncol. 2019. https://doi.org/10.1245/s10434-018-07123-8.

3. Yeo CJ, Cameron JL, Lillemoe KD, Sohn TA, Campbell KA, Sauter PK, Coleman J, Abrams RA, Hruban RH. Pancreaticoduodenectomy with or without distal gastrectomy and extended retroperitoneal lymphadenectomy for periampullary adenocarcinoma, part 2: randomized controlled trial evaluating survival, morbidity, and mortality. Ann Surg. 2002;236(3):355-66.

4. Ferrone CR, Konstantinidis IT, Sahani DV, Wargo JA, Fernandezdel Castillo C, Warshaw AL. Twenty-three years of the Warshaw operation for distal pancreatectomy with preservation of the spleen. Ann Surg. 2011;253(6):1136-9.

5. Kim H, Hwang DW, Lee JH, Shin SH, Jun ES, Kim SR, Kwak BJ, Kim TG, Park KM, Lee YJ, Kim SC. A single-center experience with the laparoscopic Warshaw technique in 122 consecutive patients. Surg Endosc. 2016;30(9):4057-64.

Publisher's Note Springer Nature remains neutral with regard to jurisdictional claims in published maps and institutional affiliations. 